\title{
Postpartum Depression: Far Reaching Impact and the Role of Empowerment
}

\section{Cristie Ritz King,,2, Stephanie M. Morgan², Casey Mace Firebaugh ${ }^{2,3}$, Tishra Beeson? Timothy J. Legg2, Rebecca Wardlow ${ }^{2}$}

${ }^{1}$ WonderInc Wellness, Red Bank, New Jersey, USA

${ }^{2}$ School of Behavioral Sciences, CalSouthern University, Costa Mesa, California, USA

${ }^{3}$ Central Washington University, Department of Health Sciences, Ellensburg, Washington, USA

Email: critzking@gmail.com

How to cite this paper: King, C. R., Morgan, S. M., Firebaugh, C. M., Beeson, T., Lrgg, T. J., \& Wardlow, R. (2021). Postpartum Depression: Far Reaching Impact and the Role of Empowerment. Open Journal of Depression, 10, **_**.

https://doi.org/10.4236/***.2021.*****

Received: $* * * * * *, * * *$

Accepted: ${ }^{* * * * * *}, * * *$

Published: $* * * * * *, * * *$

Copyright $\odot 2021$ by author(s) and Scientific Research Publishing Inc. This work is licensed under the Creative Commons Attribution International License (CC BY 4.0).

http://creativecommons.org/licenses/by/4.0/

\begin{abstract}
Postpartum depression (PPD) is a significant public and mental health issue, with long-lasting effects on mothers and children. It is expected to be the second largest problem among all general health issues by the year 2030 and $10 \%-20 \%$ of new mothers experience PPD globally. Early intervention has shown to be effective yet the consensus on best practice is not clear. This systematic review aimed to synthesize prior research to provide practical recommendations for the best practices for both intervention and prevention of PPD. The following databases were scanned: PsychiatryOnline, PsycArticles, PsycBooks, Psychology and Behavioral Sciences Collection, ERIC, and EBSCO. The search included the following keywords: postpartum depression, postpartum mental health, risk factors, intervention, prevention, efficacy, group therapy and empowerment, and perinatal and postnatal. The PRISMA checklist was used to screen studies for inclusion. Using the described search strategy, 45 articles were identified for synthesis. The following themes emerged in the literature: a variety of approaches focus on empowerment, and perceived competency. These themes appeared across various at-risk groups and in different cultural and socioeconomic groups. Recommendations for further investigation include the development of targeted treatment approaches, defining and objectifying maternal empowerment and self-efficacy, and the development of standardized training to improve provider competency so as to benefit mothers, children, communities, and the psychological community at large.
\end{abstract}

\section{Keywords}

Postpartum Depression, Depression, Maternal Health, Empowerment, Provider Competency 


\section{Introduction}

Postpartum depression (PPD) was introduced in the $4^{\text {th }}$ edition of this manual, printed in 1994 (APA, 2013). In the American Psychological Associations' $5^{\text {th }}$ Diagnostic and Statistical Manual (DSM-5), it is found under the major depressive category as a postpartum onset qualifier (APA, 2013). While PPD is marked as a qualifier rather than a distinct diagnosis, its effect is far reaching and has garnered attention from researchers across fields including but not limited to psychology, public health, nursing, obstetrics, and neurology (Kingston et al., 2012; Srivastava et al., 2015; Beck, 2002; Meltzer-Brody \& Steube, 2014; Fiorelli et al., 2015). The body of knowledge focuses on both maternal mental health and the effects on mothers and children. Research on PPD has addressed possible predicting factors and causal relationships, including poor social support, a maternal history of depression, marital or relationship strength and stressful life events (Goodman, 2009; Scott, 2014; Field, 2017; Heck, 2018). Brazeau et al. (2018) asserted that mothers' low parenting self-efficacy was linked to both postpartum depression and postpartum anxiety.

Undiagnosed and untreated maternal depression has been linked to differences in maternal response rates to infant utterances, differences in gaze and facial expression as well as lower rates of infants playing and high rates of infant withdrawal (O’Hara, 2009).

There is no universally agreed upon treatment approach for PPD. There are a number of effective treatment methods for PPD, including Interpersonal Psychotherapy (IPT), home-based interventions (sometimes called Listening Visits), and the presence of social and familial support (Barlow et al., 2010; Brock et al., 2017; Carter et al., 2010; Dixon \& Dantas, 2017; Fonseca et al., 2019; Hassert \& Krupius, 2011; Leis et al., 2009). Overall, research shows that the specificity of the intervention may not be as important as other supportive factors such as access to care and empowerment strategies (Malis et al., 2017). However, if the interventions were not designed to be accessible for new mothers of all socioeconomic backgrounds there was no intervention powerful enough to overcome non-participation (Jewell, Luecken, Gress-Smith, Crnic, \& Gonzalez, 2015).

Research has explored effective treatments for PPD from a global lens, as well as possible causal links and effects of the disorder on children (Anokye et al., 2018; Brazeau et al., 2018; Dennis et al., 2017; Field, 2017; Hairston et al., 2018; Nonnenmacher et al., 2016). However, there does not yet appear to be enough corresponding action in the healthcare system in the United States to address PPD consistently and effectively, as a number of studies illustrate that even with screening, women often do not receive the follow up treatment they need (Goodman \& Tyler-Viola, 2010; Pearlstein et al., 2009; Wilkinson \& Mulcahy, 2010). Lack of diagnosis as well as failure to follow up, even when mothers are identified through screening, are commonly identified barriers identified in the literature (Brealey et al., 2010; Kozhimannil et al., 2011). Further, mental health stigma in both medical and social settings is a common barrier in accessing 
treatment (Jewell et al., 2015; Yator et al., 2016).

Goodman and Tyler-Viola (2010) reported that many women who were marked at risk for PPD in prenatal screening, also screened positive for depression, anxiety and even panic disorder and psychosis at their six-week postpartum doctor appointments. However, only one-third of study participants received any treatment or referral for treatment according to what was documented in their obstetric medical records. Despite the fact that participants responded, "yes" to needing help and a link was identified between a yes answer and PPD diagnosis, medical records revealed that receipt of care for PPD was not always delivered, indicating lack of provider follow-up and lack on insight on barriers to accessing treatment. The majority of women who screened positive for an anxiety disorder or high levels of depressive symptoms were not identified as at-risk by their medical providers during pregnancy or postpartum. Only $15 \%$ of the positively screened women also had any evidence of mental health treatment or referrals for treatment in their medical records (Goodman \& Tyler-Viola, 2010). Screening may be an important first step. However, these results highlight how screening alone does not ensure women with risk factors for PPD ultimately receive the care they need to help prevent and treat PPD.

The purpose of this study was to systematically examine the research prevention and treatment of Postpartum Depression as well as the effects untreated PPD has on mother and child. Providing a narrative of the existing data can increase provider awareness about the importance of preventative interventions as well as effective treatment after diagnosis of PPD. Improving provider knowledge and skill set may also support a decrease in stigma experienced by mothers seeking prevention or treatment. Practical recommendations will be made to empower medical and mental health professionals to clarify their role in managing PPD in order to reduce its detrimental effects on women, families and communities. This information can be useful in assessing and changing how women are screened and treated during their peri and postnatal periods in the United States. There are negative and lingering effects of PPD on mothers and children it is necessary to clarify if there is existing data to effectively treat mothers and prevent the long-term impacts of PPD.

\section{Methods}

A systematic review of literature was performed to examine prior research to determine best practices for intervention and prevention of postpartum depression and the impact of PPD on mother and child. The following databases were searched: PsychiatryOnline, PsycArticles, PsycBooks, Psychology and Behavioral Sciences Collection, ERIC, and EBSCO. Data was sourced across fields and included obstetric experiences, behavioral science periodicals, nursing, and public health perspectives. The following keywords were used to perform the search: postpartum depression, postpartum mental health, risk factors, intervention, prevention, efficacy, group therapy and empowerment, and perinatal and post- 
natal. An initial review of the literature highlighted widely applied treatment approaches and the following terms were added to the search Cognitive Behavioral Therapy (CBT), Interpersonal Psychotherapy (IPT) and Listening Visits (LV).

The preliminary search yielded 200 studies that were reviewed for appropriateness and applicability. The literature was narrowed with a systemic analysis performed using the Preferred Reporting Items for Systematic Reviews and Meta-Analyses (PRISMA) guidelines to identify and synthesize the literature that best addressed the aim of this research. PRISMA is widely accepted and used for the analysis of data for inclusion in systematic reviews (Moher et al., 2009). The PRISMA chart is found in Figure 1.

\section{Results/Discussion}

\subsection{Studies Included}

Twenty two percent $(n=45)$ of the initial 200 articles were identified as appropriate and relevant through the defined search strategy and included in the synthesis (Figure 1). The following themes emerged: far reaching impact of PPD, variety of approaches, focus on empowerment, and provider competency.
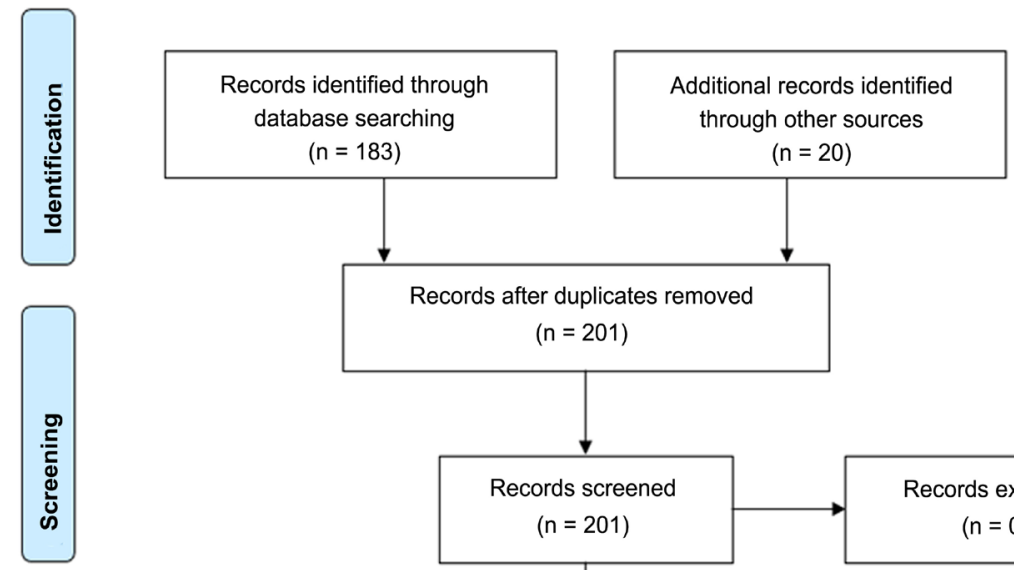

Records after duplicates removed $(n=201)$
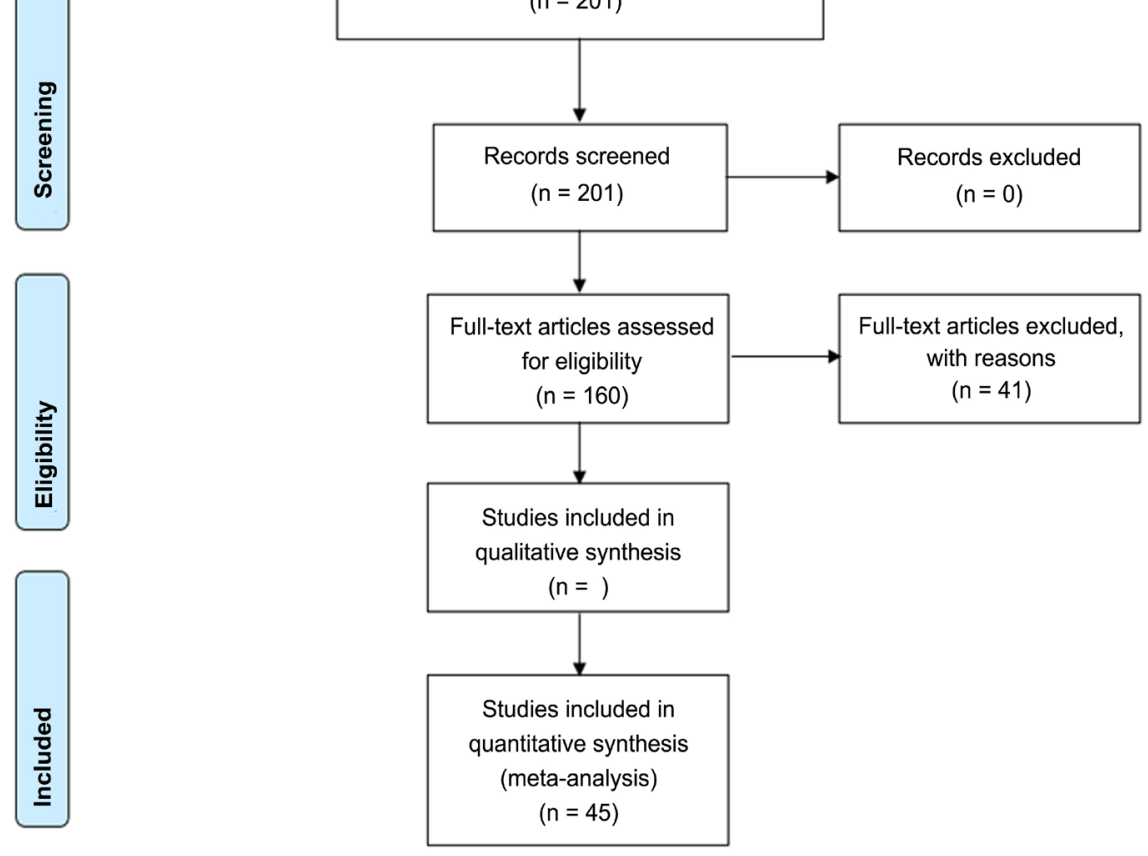

Figure 1. PRISMA flow diagram. 
The participants in each study came from a variety of backgrounds and criteria for selection were unique to each study and purpose. Some participants were chosen based on potential risk factors they shared (Mundorf et al., 2018; Dennis, Merry, Gagnon, \& Gagnon, 2017). Others are based on convenience sampling and proximity to researchers (Goodman \& Tyler-Viola, 2010). Many participants were in the United States $(\mathrm{n}=26)$ with a number of international studies $(n=19)$. Data were collected from women predominantly between the ages of 18 - 35 with few outliers.

\subsection{Far Reaching Impacts}

PPD can have detrimental effects on mothers and children (Kingston et al., 2012). The effects of PPD on child development, while not clearly linked to poor mother-infant bonding in the research, were associated with untreated postpartum depression (Kingston et al., 2015). Children of affected mothers showed greater internalizing and externalizing behaviors in grade school (Claridge, 2014). Children experience cognitive and emotional delays from preschool through grade school (Kingston et al., 2012). They are at risk for developing mental health problems such as anxiety and depression (Closa-Monasterolo et al., 2017). Research has suggested that adequate treatment can minimize long-term effect on children. In addition, children who have suffered some cognitive or emotional delays showed improvement when their mothers received treatment (Goodman et al., 2011).

The long-term impact of untreated PPD on mothers reaches beyond mental health to include biological, medical and social effects (Closa-Monasterolo et al., 2017).

PPD can result in decreased activation in the amygdala which is associated with infant-directed hostility (Fiorelli et al., 2015). Poor mother-infant bonding is also characteristic (Closa-Monasterolo et al., 2017). Mothers with PPD are at increased risk for suicidality, anxiety and prolonged states of depressed mood (Meltzer-Brody \& Stuebe, 2014). Tandon et al. (2014) found that women with untreated PPD were less likely to engage in help-seeking behaviors and utilize supports available. States such as New Jersey, Illinois, and West Virginia have adopted screening protocols for PPD, and many providers participate in PPD screening regardless of legal mandate. Despite these improvements, estimated instances of undiagnosed and untreated PPD are as high as $80 \%$ globally (Brüggmann et al., 2017).

\subsection{Variety of Approaches}

Treatments involving education and early support for mothers were found to be helpful in addressing early symptoms as well as reducing the long-term detrimental effects of PPD (Brazeau et al., 2018). Some evidence-based programs were prominent across the literature and included Mothers \& Babies (MB), Interpersonal Psychotherapy (IPT) and Mindfulness based programs (Malis et al., 
2017). MB is a manualized intervention used for prevention and treatment of PPD. It is based on Cognitive Behavioral Theory and Attachment Theory and focuses on mood, stress and attachment of mother and infant (Tandon et al., 2018). IPT is a brief and present-focused therapy that centers on the interpersonal context of depression (Carter et al., 2010). Mindfulness interventions typically involve training in concepts of attention and focus on the present moment to encourage a more open and less judgemental view of any situation (Sheydaei et al., 2017). There was no uniform approach and the research consistently suggested that providers take an individualized, patient-centered approach (Malis et al., 2017; Mao et al., 2012).

Access to care was shown to be an important factor in determining the success of any intervention. Women across high and low risk groups often had barriers to treatment due to stigma or fear and shame to disclose symptoms to doctors or untrusted professionals (Jewell et al., 2015). Regardless of treatment setting (e.g. group therapy in a community center or hospital, Listening Visits in the home or individual psychotherapy in a private office), if women encountered too many barriers to stable access treatment, intervention was ineffective, regardless of approach (McFarlane et al., 2016; Segre et al., 2015; Yator et al., 2016). However, if women were provided solutions to barriers such as transportation or childcare, or offered community based treatment in their own home with a trusted provider, then there was a higher success rate unrelated to treatment approach, intervention, or risk level (Pessagno \& Hunter, 2013). Effective interventions include those that address the whole person, and focus on behavioral and cognitive changes, emotional regulation strategies and education that can increase sense of wellness and self-efficacy (Letourneau et al., 2017; Kleinman \& Reizer, 2018; Mao et al., 2012; Thitipitchayanant et al., 2018).

\subsection{Focus on Empowerment}

The literature highlighted the success of interventions that focused on education and empowerment of mothers (Tandon et al., 2018; McFarlane et al., 2016; Thitipitchayanant et al., 2018; Turan et al., 2018). For the purpose of this study, empowerment is defined as the increasing self-efficacy, knowledge and competence that comes from working toward a self-determined goal (Cattaneo \& Chapman, 2010). Empowerment was either the focus of the intervention or a byproduct reported by the mothers across studies. The connection between preceived self-efficacy and reduced PPD symptoms was noted (Brazeau et al., 2018).

Women with a stronger support system self-rate as having increased ability to parent and higher levels of self-efficacy are linked to fewer PPD symptoms (Anokye et al., 2018; Brazeau et al., 2018). Parental self-efficacy is bolstered through strenghts-based, empowerement focused interventions. Empowerment approaches resulted in self-reported decreased in symptompatology associated with PPD, lower self-report of pain and stress, and improved emotional regulation skills (Fonseca et al., 2019; Mao et al., 2012; Thitipitchayanant et al., 2018). Empowerment was linked to greater sense and was identified as a protective 
factor for postpartum depression and a supportive factor in recovery (Kleinman \& Reizer, 2018; Tandon et al., 2018; McFarlane et al., 2016).

\subsection{Provider Competency}

Mothers with untreated PPD go on to experience acute symptoms including fatigue, anxiety, feelings of inadequacy or loneliness, interrupted sleep and irritability. They are at increased risk to develop future mental and physical health problems (Meltzer-Brody \& Stuebe, 2014; Fiorelli et al., 2015). Mothers with postpartum depression are also less likely to seek out basic care for themselves or their children which compounds the problems they encounter as a result of PPD (Tandon et al., 2014). It is important that providers understand the risks, recommended treatment approaches, the usefulness of the provider-patient alliance, and the consequences of nontreatment in order to competently treat mothers at risk for or experiencing PPD (Segre et al., 2015).

Liu and Tronick (2013) identified a shortage of competent services. Their study spanned over three years and was one of very few studies focused on racial or cultural risk factors. It is especially important, in such a heterogenous country that when discussing finding the best predictors or solutions for problems such as postpartum depression providers exercise cultural competency and consider race and cultural factors in their conceptualization (Maxwell et al., 2019). Mothers of marginalized group are far more likely to experience medical and mental health consequences associated with birth and are largely underpresented in research (Abrams \& Curran, 2007; Sterling et al., 2011). It is essential the providers are competent in personalizing their approach and using a color conscious lens (Maxwell et al., 2019).

Risk factors vary among women and cultural factors and history of mental health symptomatology and diagnosis should be considered. Social stressors such as lower socioeconomic status, poor community support, lack of access to health care, food insecurity, refugee or immigrant status, and weak or challenged relationship with father can all increase risk and a combination of factors poses the highest risk (Dennis et al., 2017; Field, 2017; Corrigan et al., 2015). Strong social support and a strong relationship with a care provider were identified as protective factors (O'Mahen \& Flynn, 2018; Goodman, 2009). This suggests that provider insight, level of competency, assessment of a wider range of risk factors, and ability to develop a relationship with mother can improve treatment outcomes (Austin, 2004). Providers who offer patient-centered care are more likely to have a strong alliance with mother and improved treatment outcomes (Wissow, Brown, \& Krupnick, 2010).

Lack of competency was identified across studies (Goodman \& Tyler-Viola, 2010; Hansotte et al., 2017). Despite the prevelance of risk factors and consequences identified, underdiagnosis or lack of screening was reported across several studies (Hansotte et al., 2017; Goodman \& Tyler-Viola, 2010; Glasser et al., 2016). Zee-van den Berg et al. (2017) reported non-use of identified screenings 
by obstetricians or pediatricians in the postpartum window. Providers reported only assessing for PPD based on interpretation and observation of the mother's mood (Heneghan et al., 2007).

This is problematic because it was also noted many women are still afraid to report symptoms for a variety of reasons including but not limited to interpretation of the wording on screenings as more intense than their lived experience, preference for informal conversation, fear of admitting something is wrong, and fear of their child being removed from their care (Brealey et al., 2010; Thorsteinsson et al., 2018). If providers are not competent in the unique presentation of symptoms, intune with the mother's presentation and way of connecting with the provider, and reluctant to use reliable assessment tools, mothers may go undiagnosed and may not receive critical treatment.

Finally, Goodman \& Tyler-Viola (2010) alluded to lowered competency in noting that even if women were diagnosed, follow up with a provided referral was inconsistent. This lack of follow-through was attributed to lack of provider follow-up after a preliminary diagnosis. Provider connection has been shown to be a protective factor and competent providers should make efforts to facilitate access and encourage and support the linkage to services (Goodman, 2009; O’Hara, 2014).

\subsection{Limitations}

A systematic review is a theoretical approach that relies on the findings of prior research. Therefore, it is necessary to illuminate the possibility of undetected bias in the studies examined that may not have been identified when articles were considered for inclusion in this review. Criteria were not limited to one country or geographic region, however, the majority of studies were conducted in the United States, and in so much, the findings of this review are not generalizable on a global level.

Additionally, studies examining the effectiveness of psychopharmocological interventions were not included as their scope was too narrow in regard to the aim of this review. While this review does suggest non-pharmacological interventions and reccomendations for treatment, it should be noted that psychopharmaceutical interventions are linked to high rates of treatment efficacy in the literature (Fitelson et al., 2010; Frieder et al., 2019; Limandri, 2019).

Finally, the majority of the articles included examined short-term effects of intervention on mothers and children $(\mathrm{n}=36)$, and few attended to the long-term efficacy of interventions $(n=9)$. Notable long-term studies are seen in the field of attachment research and suggest a stronger mother-child bond and improved interactions do have long-term effects on both mother and child (Brazeau et al., 2018; Hong \& Park, 2012). This assertion dates back to the work of Bowlby (1958) who linked attachment styles with long-term effects on both mother and child. This particular review is limited in providing insights for the long-term impact of treatment recommendations and improved provider competency. 


\subsection{Implications and Future Research}

The literature suggested that a woman with PPD may not feel confident about her parenting skills, which in turn may impede bonding as well as perpetuate affective outcomes associated with PPD. This can create a continuing cycle of feeling unwell and insecure. Interventions aimed at increasing feelings of empowerment may lead to prevention and mitigation of PPD symptoms and resulting outcomes for both mothers and infants. These findings represent a critical component inherent to the practical recommendations from this review.

The ramifications of undiagnosed and mistreated PPD impact both the wellness of mother and child and can have long lasting and far-reaching consequences on the mother, child, family, and community. Eliminating barriers to screening and risk assessment may present key opportunities for new policy and practice initiatives aimed at reducing incidence of PPD that goes undetected or untreated. Future research could include quantitative investigation focused on the objectification of risk factors, instances of screening use, instances of provider follow-up post-screening, the development of targeted treatment approaches, defining and objectifying maternal empowerment and self-efficacy, and the development of standardized training to improve provider competency. An experimental pre/post design could explore provider perception of competency following the implementation of a standardized training program.

\section{Conclusion}

This review aimed to identify the most effective treatments and/or consistent treatment approaches to PPD in order to provide direct practice recommendations. Research did not point to an agreeable, widely utilized approach to treatment. Additionally, it alluded that providers were not competent in providing individualized, target, culturally informed care. Swanson and Chermack (2013) noted that practitioners are more inclined toward a broad, try-everything approach. Similarly, the focus of most research designs is narrow and it is difficult to translate findings into practice (Swanson \& Chermack, 2013). This review illuminated that empowering women to feel confident about being mothers is in itself a strong intervention and can function as a powerful prevention strategy (Mao et al., 2012; McFarlane et al., 2016; Tandon et al., 2018). When designing clinical practices and making recommendations for treatment, it is important to keep these findings at the forefront.

\section{Conflicts of Interest}

The authors declare no conflicts of interest regarding the publication of this paper.

\section{References}

Abrams, L., \& Curran, L. (2007). Not Just a Middle Class Affliction: Crafting a Social Work Research Agenda on Postpartum Depression. Health \& Social Work, 32, 
289-296. https://doi.org/10.1093/hsw/32.4.289

Anokye, R., Acheampong, E., Budu-Ainooson, A., Obeng, E. I., \& Akwasi, A. G. (2018). Prevalence of Postpartum Depression and Interventions Utilized for Its Management. Annals of General Psychiatry, 17, 1-8. https://doi.org/10.1186/s12991-018-0188-0

APA, American Psychiatric Association (2013). Diagnostic and Statistical Manual of Mental Disorders (5th ed.). Arlington, VA: APA. https://doi.org/10.1176/appi.books.9780890425596

Austin, M.-P. (2004). Antenatal Screening and Early Intervention for "Perinatal" Distress, Depression and Anxiety: Where to from Here? Archives of Women's Mental Health, 7, 1-6. https://doi.org/10.1007/s00737-003-0034-4

Barlow, J., McMillan, A. S., Kirkpatrick, S., Ghate, D., Barnes, J., \& Smith, M. (2010). Health-Led Interventions in the Early Years to Enhance Infant and Maternal Mental Health: A Review of Reviews Jane Barlow et al. Health-Led Interventions in the Early Years. Child \& Adolescent Mental Health, 15, 178-185. https://doi.org/10.1111/j.1475-3588.2010.00570.x

Beck, C. T. (2002). Theoretical Perspectives of Postpartum Depression and Their Treatment Implications. The American Journal of Maternal/Child Nursing, 27, 282-287. https://doi.org/10.1097/00005721-200209000-00008

Bowlby, J. (1958). The Nature of the Child's tie to His Mother. International Journal of Psychoanalysis, 39, 350-371.

Brazeau, N., George, C., Reisz, S., \& Jacobvitz, D. (2018). Understanding the Connection between Attachment Trauma and Maternal Self-Efficacy in Depressed Mothers. Infant Mental Health Journal, 39, 30-43. https://doi.org/10.1002/imhj.21692

Brealey, S., Hewitt, C., Green, J., Morrell, J., \& Gilbody, S. (2010). Screening for Postnatal Depression-Is It Acceptable to Women and Healthcare Professionals? A Systematic Review and Meta-Synthesis. Journal of Reproductive \& Infant Psychology, 28, 328-344. https://doi.org/10.1080/02646838.2010.513045

Brock, R. L., O’Hara, M. W., \& Segre, L. S. (2017). Depression Treatment by Non-Mental-Health Providers: Incremental Evidence for the Effectiveness of Listening Visits. American Journal of Community Psychology, 59, 172-183.

https://doi.org/10.1002/ajcp.12129

Brüggmann, D., Wagner, C., Klingelhöfer, D., Schoffel, L., Bendels, M., Louwen, F., Jaque, J., \& Groneberg, D. A. (2017). Maternal Depression Research: Socioeconomic Analysis and Density-Equalizing Mapping of the Global Research Architecture. Archives of Women's Mental Health, 20, 25-37. https://doi.org/10.1007/s00737-016-0669-6

Carter, W., Grigoriadis, S., Ravitz, P., \& Ross, L. E. (2010). Conjoint IPT for Postpartum Depression: Literature Review and Overview of a Treatment Manual. American Journal of Psychotherapy, 64, 373-392. https://doi.org/10.1176/appi.psychotherapy.2010.64.4.373

Cattaneo, L., \& Chapman, A. (2010). The Process of Empowerment a Model for Use in Research and Practice. The American Psychologist, 65, 646-659. https://doi.org/10.1037/a0018854

Claridge, A. M. (2014). Efficacy of Systemically Oriented Psychotherapies in the Treatment of Perinatal Depression: A Meta-Analysis. Archives of Women's Mental Health, 17, 3-15. https://doi.org/10.1007/s00737-013-0391-6

Closa-Monasterolo, R., Gispert-Llaurado, M., Canals, J., Luque, V., Zaragoza-Jordana, M., Koletzko, B. et al. (2017). The Effect of Postpartum Depression and Current Mental Health Problems of the Mother on Child Behaviour at Eight Years. Maternal \& Child Health Journal, 21, 1563-1572. https://doi.org/10.1007/s10995-017-2288-x 
Corrigan, C. P., Kwasky, A. N., \& Groh, C. J. (2015). Social Support, Postpartum Depression, and Professional Assistance: A Survey of Mothers in the Midwestern United States. The Journal of Perinatal Education, 24, 48-60. https://doi.org/10.1891/1058-1243.24.1.48

Dennis, C.-L., Merry, L., Gagnon, A., \& Gagnon, A. J. (2017). Postpartum Depression Risk Factors among Recent Refugee, Asylum-Seeking, Non-Refugee Immigrant, and Canadian-Born Women: Results from a Prospective Cohort Study. Social Psychiatry \& Psychiatric Epidemiology, 52, 411-422. https://doi.org/10.1007/s00127-017-1353-5

Dixon, S., \& Dantas, J. A. R. (2017). Best Practice for Community-Based Management of Postnatal Depression in Developing Countries: A Systematic Review. Health Care for Women International, 38, 118-143. https://doi.org/10.1080/07399332.2016.1255213

Field, T. (2017). Postpartum Depression Effects, Risk Factors and Interventions: A Review. Clinical Depression, 3, Article ID: 1000122.

https://doi.org/10.4172/2572-0791.1000122

Fiorelli, M., Aceti, F., Marini, I., Giacchetti, N., Macci, E., Tinelli, E. et al. (2015) Magnetic Resonance Imaging Studies of Postpartum Depression: An Overview. Behavioural Neurology, 2015, Article ID: 913843. https://doi.org/10.1155/2015/913843

Fitelson, E., Kim, S., Baker, A. S., \& Leight, K. (2010). Treatment of Postpartum Depression: Clinical, Psychological and Pharmacological Options. International Journal of Women's Health, 3, 1-14. https://doi.org/10.2147/IJWH.S6938

Fonseca, A., Monteiro, F., Alves, S., Gorayeb, R., \& Canavarro, M. C. (2019). Be a Mom, a Web-Based Intervention to Prevent Postpartum Depression: The Enhancement of Self-Regulatory Skills and Its Association with Postpartum Depressive Symptoms. Frontiers in Psychology, 10, 265. https://doi.org/10.3389/fpsyg.2019.00265

Frieder, A., Fersh, M., Hainline, R., \& Deligiannidis, K. M. (2019). Pharmacotherapy and Postpartum Depression: Current Approaches and Novel Drug Treatment. CNS Drugs, 33, 265-282. https://doi.org/10.1007/s40263-019-00605-7

Glasser, S., Levinson, D., Bina, R., Munitz, H., Horev, Z., \& Kaplan, G. (2016). Primary Care Physicians' Attitudes toward Postpartum Depression: Is It Part of Their Job? Journal of Primary Care \& Community Health, 7, 24-29. https://doi.org/10.1177/2150131915611827

Goodman, J. H. (2009). Women's Attitudes, Preferences, and Perceived Barriers to Treatment for Perinatal Depression. Birth, 36, 60-69. https://doi.org/10.1111/j.1523-536X.2008.00296.x

Goodman, J. H., \& Tyler-Viola, L. (2010). Detection, Treatment, and Referral of Perinatal Depression and Anxiety by Obstetrical Providers. Journal of Women's Health, 19, 477-490. https://doi.org/10.1089/jwh.2008.1352

Goodman, S. H., Rouse, M. H., Connell, A. M., Broth, M. R., Hall, C. M., \& Heyward, D. (2011). Maternal Depression and Child Psychopathology: A Meta-Analytic Review. Clinical Child \& Family Psychology Review, 14, 1-27. https://doi.org/10.1007/s10567-010-0080-1

Hairston, S., Handelzalts, I. E., Assis, J., \& Kovo, M. (2018). Postpartum Bonding Difficulties and Adult Attachment Styles: The Mediating Role of Postpartum Depression and Childbirth-Related PTSD. Infant Mental Health Journal, 39, 198-208.

https://doi.org/10.1002/imhj.21695

Hansotte, E., Payne, S. I., \& Babich, S. M. (2017). Positive Postpartum Depression Screening Practices and Subsequent Mental Health Treatment for Low-Income Women in Western Countries: A Systematic Literature Review. Public Health Reviews, 38, Article No. 3. https://doi.org/10.1186/s40985-017-0050-y 
Hassert, S., \& Kurpius, S. E. R. (2011). Latinas and Postpartum Depression: Role of Partner Relationship, Additional Children, and Breastfeeding. Journal of Multicultural Counseling and Development, 39, 90-100. https://doi.org/10.1002/j.2161-1912.2011.tb00143.x

Heck, J. L. (2018). Screening for Postpartum Depression in American Indian/Alaska Native Women: A Comparison of Two Instruments. American Indian \& Alaska Native Mental Health Research: The Journal of the National Center, 25, 74-102. https://doi.org/10.5820/aian.2502.2018.74

Heneghan, A. M., Morton, S., \& DeLeone, N. L. (2007). Paediatricians' Attitudes about Discussing Maternal Depression during a Paediatric Primary Care Visit. Child Care Health Development, 33, 333-339. https://doi.org/10.1111/j.1365-2214.2006.00648.x

Hong, Y. R., \& Park, J. S. (2012). Impact of Attachment, Temperament and Parenting on Human Development. Korean Journal of Pediatrics, 55, 449-454.

https://doi.org/10.3345/kjp.2012.55.12.449

Jewell, S. L., Luecken, L. J., Gress-Smith, J., Crnic, K. A., \& Gonzales, N. A. (2015). Economic Stress and Cortisol among Postpartum Low-Income Mexican American Women: Buffering Influence of Family Support. Behavioral Medicine, 41, 138-144. https://doi.org/10.1080/08964289.2015.1024603

Kingston, D., McDonald, S., Austin, M.-P., \& Tough, S. (2015). Association between Prenatal and Postnatal Psychological Distress and Toddler Cognitive Development: A Systematic Review. PLOS ONE, 10, e0126929.

http://search.ebscohost.com/login.aspx?direct=true\&db=edb\&AN=102970968\&site=ed s-live\&scope $=$ site https://doi.org/10.1371/journal.pone.0126929

Kingston, D., Tough, S., \& Whitfield, H. (2012). Prenatal and Postpartum Maternal Psychological Distress and Infant Development: A Systematic Review. Child Psychiatry \& Human Development, 43, 683-714. https://doi.org/10.1007/s10578-012-0291-4

Kleinman, C., \& Reizer, A. (2018). Negative Caregiving Representations and Postpartum Depression: The Mediating Roles of Parenting Efficacy and Relationship Satisfaction. Health Care for Women International, 39, 79-94. https://doi.org/10.1080/07399332.2017.1369080

Kozhimannil, K. B., Adams, A. S., Soumerai, S. B., Busch, A. B., \& Huskamp, H. A. (2011). New Jersey's Efforts to Improve Postpartum Depression Care Did Not Change Treatment Patterns for Women on Medicaid. Health Affairs, 30, 293-301. https://doi.org/10.1377/hlthaff.2009.1075

Leis, J. A., Mendelson, T., Tandon, D., \& Perry, D. F. (2009). A Systematic Review of Home-Based Interventions to Prevent and Treat Postpartum Depression. Archives of Women's Mental Health, 12, 3-13. https://doi.org/10.1007/s00737-008-0039-0

Letourneau, N. L., Dennis, C., Cosic, N., \& Linder, J. (2017). The Effect of Perinatal Depression Treatment for Mothers on Parenting and Child Development: A Systematic Review. Depression \& Anxiety, 34, 928-966. https://doi.org/10.1002/da.22687

Limandri, B. J. (2019). Postpartum Depression: When the Stakes Are the Highest. Journal of Psychosocial and Mental Health Services, 57, 9-14. https://doi.org/10.3928/02793695-20191016-03

Liu, C., \& Tronick, E. (2013). Rates and Predictors of Postpartum Depression by Race and Ethnicity: Results from the 2004 to 2007 New York City PRAMS Survey (Pregnancy Risk Assessment Monitoring System). Maternal \& Child Health Journal, 17, 1599-1610. https://doi.org/10.1007/s10995-012-1171-Z

Malis, F. R., Meyer, T., \& Gross, M. M. (2017). Effects of an Antenatal Mindfulness-Based 
Childbirth and Postpartum Programme on the Postpartum Experience of Mothers: A Qualitative Interview Study. BMC Pregnancy \& Childbirth, 17, Article No. 57. https://doi.org/10.1186/s12884-017-1240-9

Mao, H.-J., Li, H.-J., Chiu, H., Chan, W.-C., \& Chen, S.-L. (2012). Effectiveness of Antenatal Emotional Self-Management Training Program in Prevention of Postnatal Depression in Chinese Women. Perspectives in Psychiatric Care, 48, 218-224. https://doi.org/10.1111/j.1744-6163.2012.00331.x

Maxwell, D., Robinson, S. R., \& Rogers, K. (2019). “I Keep It to Myself”: A Qualitative Meta-Interpretive Synthesis of Experiences of Postpartum Depression among Marginalised Women. Health \& Social Care in the Community, 27, e23-e36. https://doi.org/10.1111/hsc. 12645

McFarlane, E., Burrell, L., Duggan, A., \& Tandon, D. (2016). Outcomes of a Randomized Trial of a Cognitive Behavioral Enhancement to Address Maternal Distress in Home Visited Mothers. Maternal and Child Health Journal, 21, 475-484. https://doi.org/10.1007/s10995-016-2125-7

Meltzer-Brody, S., \& Stuebe, A. (2014). The Long-Term Psychiatric and Medical Prognosis of Perinatal Mental Illness. Best Practice \& Research. Clinical Obstetrics \& Gynaecology, 28, 49-60. https://doi.org/10.1016/j.bpobgyn.2013.08.009

Moher, D., Liberati, A., Tetzlaff, J., \& Altman, D. G., The PRISMA Group (2009). Preferred Reporting Items for Systematic Reviews and Meta-Analyses: The PRISMA Statement. Annals of Internal Medicine, 151, 264-269. https://doi.org/10.7326/0003-4819-151-4-200908180-00135

Mundorf, C., Shankar, A., Moran, T., Heller, S., Hassan, A., Harville, E., \& Lichtveld, M. (2018). Reducing the Risk of Postpartum Depression in a Low-Income Community through a Community Health Worker Intervention. Maternal and Child Health Journal, 22, 520-528. https://doi.org/10.1007/s10995-017-2419-4

Nonnenmacher, N., Noe, D., Ehrenthal, J., \& Reck, C. (2016). Postpartum Bonding: The Impact of Maternal Depression and Adult Attachment Style. Archives of Women's Mental Health, 19, 927-935. https://doi.org/10.1007/s00737-016-0648-y

O'Hara, M. W. (2009). Postpartum Depression: What We Know. Journal of Clinical Psychology, 65, 1258-1269. https://doi.org/10.1002/jclp.20644

O'Hara, M. W. (2014). Psychosocial and Psychological Interventions Reduce the Risk of Postnatal Depression Compared with Standard Care. Evidence Based Nursing, 17, 38-39.

O’Mahen, H. A., \& Flynn, H. A. (2018). Preferences and Perceived Barriers to Treatment for Depression during the Perinatal Period. Journal of Women's Health, 17, 1301-1309. https://doi.org/10.1089/jwh.2007.0631

Pearlstein, T., Howard, M., Salisbury, A., \& Zlotnick, C. (2009). Postpartum Depression. American Journal of Obstetrics and Gynecology, 200, 357-364. https://doi.org/10.1016/j.ajog.2008.11.033

Pessagno, R. A., \& Hunker, D. (2013). Using Short-Term Group Psychotherapy as an Evidence-Based Intervention for First-Time Mothers at Risk for Postpartum Depression. Perspectives in Psychiatric Care, 49, 202-209. https://doi.org/10.1111/j.1744-6163.2012.00350.x

Scott, D. A. (2014). Attachment Ratings in Couples as Predictors of Depressive Symptomatology Postpartum. Journal of Reproductive \& Infant Psychology, 32, 377-387. https://doi.org/10.1080/02646838.2014.940517

Segre, L. S., Brock, R. L., \& O’Hara, M. W. (2015). Depression Treatment for Impoverished Mothers by Point-of-Care Providers: A Randomized Controlled Trial. Journal of 
Sheydaei, H., Ghasemzadeh, A., Lashkari, A., \& Kajani, P. G. (2017). The Effectiveness of Mindfulness Training on Reducing the Symptoms of Postpartum Depression. Electronic Physician, 9, 4753-4758. https://doi.org/10.19082/4753

Srivastava, A. S., Mara, B., Pandey, S., Tripathi, M. N., Pandit, B., \& Yadav, J. S. (2015). Psychiatric Morbidities in Postpartum Females: A Prospective Follow-Up during Puerperium. Open Journal of Psychiatry \& Allied Sciences, 6, 101-105. https://doi.org/10.5958/2394-2061.2015.00005.1

Sterling, B., Fowles, E., Kim, S., Latimer, L., \& Walker, L. O. (2011). Ethnic-Specific Perceptions of Altered Control among American Women Implications for Health Programs after Pregnancy. Health Care for Women International, 32, 39-56. https://doi.org/10.1080/07399332.2010.529353

Swanson, R. A., \& Chermack, T. J. (2013). Theory Building in Applied Disciplines. San Francisco, CA: Berrett-Koehler Publications Inc.

Tandon, S. D., Leis, J. A., Mendelson, T., Perry, D. F., \& Kemp, K. (2014). Six-Month Outcomes from a Randomized Controlled Trial to Prevent Perinatal Depression in Low-Income Home Visiting Clients. Maternal and Child Health Journal, 18, 873-881. https://doi.org/10.1007/s10995-013-1313-y

Tandon, S. D., Ward, E. A., Hamil, J. L., Jimenez, C., \& Carter, M. (2018). Perinatal Depression Prevention through Home Visitation: A Cluster Randomized Trial of Mothers and Babies 1-on-1. Journal of Behavioral Medicine, 41, 641-652.

https://doi.org/10.1007/s10865-018-9934-7

Thitipitchayanant, K., Somrongthong, R., Kanchanakharn, N., \& Kumar, R. (2018). Effectiveness of Self-Empowerment-Affirmation-Relaxation (Self-EAR) Program for Postpartum Blues Mothers: A Randomize Controlled Trial. Pakistan Journal of Medical Sciences, 34, 1488-1493. https://doi.org/10.12669/pjms.346.15986

Thorsteinsson, E. B., Loi, N. M., \& Farr, K. (2018). Changes in Stigma and Help-Seeking in Relation to Postpartum Depression: Non-Clinical Parenting Intervention Sample. PeerJ, 6, e5893. https://doi.org/10.7717/peerj.5893

Turan, J. M., Darbes, L. A., Musoke, P. L., Kwena, Z., Rogers, A. J., Hatcher, A. M. et al. (2018). Development and Piloting of a Home-Based Couples Intervention during Pregnancy and Postpartum in Southwestern Kenya. AIDS Patient Care \& STDs, 32, 92-103. https://doi.org/10.1089/apc.2017.0285

Wilkinson, R. B., \& Mulcahy, R. (2010). Attachment and Interpersonal Relationships in Postnatal Depression. Journal of Reproductive \& Infant Psychology, 28, 252-265. https://doi.org/10.1080/02646831003587353

Wissow, L. S., Brown, J. D., \& Krupnick, J. (2010). Therapeutic Alliance in Pediatric Primary Care: Preliminary Evidence for a Relationship with Physician Communication Style and Mothers' Satisfaction. Journal of Developmental \& Behavioral Pediatrics, 31, 83-91. https://doi.org/10.1097/DBP.0b013e3181cda770

Yator, O., Mathai, M., Vander Stoep, A., Rao, D., \& Kumar, M. (2016). Risk Factors for Postpartum Depression in Women Living with HIV Attending Prevention of Mother-to-Child Transmission Clinic at Kenyatta National Hospital, Nairobi. AIDS Care, 28, 884-889. https://doi.org/10.1080/09540121.2016.1160026

Zee-van den Berg, A., Boere-Boonekamp, M., IJzerman, M., Haasnoot-Smallegange, R., \& Reijneveld, S. (2017). Screening for Postpartum Depression in Well-Baby Care Settings: A Systematic Review. Maternal \& Child Health Journal, 21, 9-20.

https://doi.org/10.1007/s10995-016-2088-8 